\title{
Relations and Trust: Themes, Concepts and Relationships
}

\author{
Ying-Shao Chang and Jen-Hwa Kuo
}

\begin{abstract}
The purpose of this paper wants to map the research between relations and trust and to investigate the key concepts, themes, and their relationships of literatures in the past decade. In this study, bibliometric and social network analysis techniques are used to investigate the intellectual pillars of the literatures about relations and trust. By analyzing 85,034 citations of 1,995 articles published in SSCI journal in relations and trust area between 2007 and 2012. The results of the mapping can help identify the research direction of relations and trust research and provide a valuable tool for researchers to access the literature in this area.
\end{abstract}

Index Terms-Relations, trust, co-citation, social network.

\section{INTRODUCTION}

The past decade has especially seen extensive research on relations and trust. Coleman J.S. (1990) discussions relations and trust in social institution and social theory [1]. People those who working together have the relationship and need to trust [2]. As the literature on trust reveals, and as developed here, "trust" is a term with meanings [3]. Yet even though relations and trust has established itself as an academic discipline, its establishment has been a slow process because researchers in this area prefer to publish their best work in more established journals.

Another major obstacle to the development of relations and trust lies in the subject's unusually high degree of interaction with other disciplines. This overlapping blurs the boundaries of relations and trust and as a result its distinct theoretical model and analytical tools are unjustly attributed to other competing fields. With limited resources contributing to the development of relations and trust, the cross-fertilization of ideas between scholars of relations and trust will be much more difficult to obtain. Consequently, while there is no doubt that there is an area or field of relations and trust, the question remains somehow unclear on what it is, how good its work is, and what are its prospects and needs for future development.

This analysis reveals a wealth of information, for example the lists of highly-cited books, articles and authors presented here The aim of this study is to provide relations and trust researchers with a unique map to better understand relations and trust related publications and to provide a systematic and objective mapping of different themes and concepts in the development of relations and trust field.

Manuscript received December 30, 2012; revised March 13, 2013.

Ying-Shao Chang is with the Department of Mass Communication of Chang Jung Christian University; Executive of Star Radio of Chang Jung Christian University Tainan, Taiwan (e-mail: jenny757@ms29.hinet.net).

Jen-Hwa Kuo is with the Graduate School of Business and Operations Management, Chang Jung Christian University, Tainan, Tainwan (e-mail: dynaopto@gmail.com).
This study also attempts to help identify the linkage among different publications and confirm their status and positions in their contribution to the development of relations and trust field. The principal methods used are citation and co-citation analysis, social network analysis, plus a factor analysis which is performed to identify the invisible network of knowledge generation underlying the relations and trust literature.

\section{STUdies OF ACADEMIC LiterATURE}

There are a number of techniques that can be used to study a body of literature. Most frequent is the simple literature review where a highly subjective approach is used to structure the earlier work. Objective and quantitative techniques have recently become popular with more databases available online for use. These techniques adopt author citations, co-citations, and systematic review to examine the invisible knowledge network in the communication process by means of written and published works of a given field [4]. These techniques are attractive because they are objective and unobtrusive [5].

Several studies have used the bibliometric techniques to study the literature of management research. For example, Ponzi explored the intellectual structure and interdisciplinary breadth of knowledge management in its early stage of development, using principle component analysis on an author co-citation frequency matrix [6]; Etemad identified the most influential authors and studies in electronic commerce field by using citation analysis [7]; Ramos-Rodriguez and Ruiz-Navarro examined the intellectual structure change of strategic management research by conducting a bibliometric study of the Strategic Management Journal [8]; Acedo and Casillas explored the research paradigms of international management research by applying factorial analysis techniques in an author co-citation study[9]. Chan, Seow and Tam used citations from accounting dissertations completed during 1999-2003 to provide a ranking of accounting journals [10]. To the best of our knowledge, no similar study has been conducted on the current research of knowledge management. Therefore this study aims to fill a gap in knowledge management literature by applying citation and co-citation analysis to a representative sample of recent research on knowledge management was collected by the Science Citation Index and Social Sciences Citation Index.

\section{Methodology}

The citation data used in this study included journal articles, authors, publication outlets, publication dates, and cited references. Based on the objective of this study, the authors explored the intellectual structure of relations and 
trust between 2003 and 2012. This time period was chosen because contemporary relations and trust studies of the last decade represent the most update and probably also the most important research on relations and trust. Citation and co-citation analysis is the main method for this study. First, the databases were identified as the sources of relations and trust publications. Then data collection and analysis techniques were designed to collect information about topics, authors, and journals on relations and trust research.

In the second stage, the collected data were analyzed and systematized by sorting, screening, summing, sub-totaling, and ranking. After a series of operations, key nodes in the invisible network of knowledge in accounting standards were identified and the structures developed. In the final stage, the co-citation analysis was used and the knowledge network of relations and trust was mapped to describe the knowledge distribution process in relations and trust area.

In this study, the Science Citation Index (SCI) and Social Sciences Citation Index (SSCI) were used for analysis. The SCI and SSCI are widely used databases, which include citations published in over 8000 world's leading scholarly journals. While there are arguments that other online databases might also be used for such analysis, using SCI and SSCI provided the most comprehensive and the most accepted databases of accounting standards publications.

Unlike other prior studies, the data used in this study were not drawn from journals chosen by peer researcher [11]. Instead, the entire databases of SCI and SSCI from 2003 to 2012 served as the universe for analysis. In order to collect the data, and used "key word" method which utilizes the SCI and SSCI databases key word search in article's title and abstract. Using "Accounting standards" as key word, this study collected 1,995 journal articles which further cited 85,034 publications as references. The cited references in these papers included both books and journal articles.

\section{RESUltS}

\section{A. Citation Analysis}

To identify the key publications and scholars that have laid down the ground work of knowledge management research, citation data were tabulated for each of the 1,995 source documents and 85,034 references using the Excel package. The citation analysis produced interesting background statistics, as shown in the following tables. Table I lists the most cited journals in accounting standards area in the last decade, among which Journal of Marketing, Academy of Management Review, and Academy of Management Journal are the top three most cited journals, followed by Journal of Personality and Social Psychology and Journal of Applicative Psychology. The general pattern of the most cited journals shows that marketing research, management journals, social science concern journals.

The most influential documents with the most citation and the most influential scholars were then identified by their total counts of citation within the selected journal articles. As shown in Table II, the three most cited relations and trust publication between 2003 and 2007 (the first five years) was Putnam R., 1993, Making Democracy Work on. For the second five years (2008-2012), the first cited one was Making Democracy Work, the second cites one was Foundations of social theory, the third most cited was Mayer R.C.'s paper An Integrative Model of Organizational Trust and the followed was Morgan RM's paper The Commitment-Trust Theory of Relationship Marketing and Putnam R.D.'s paper The collapse and revival of American democracy (Table III).

TABLE I: The Most FreQuentLy CiTED JOURNALS: 2003-2012

\begin{tabular}{lc}
\hline \hline \multicolumn{1}{c}{ Journals } & Total Citations \\
\hline Journal of Marketing & 1255 \\
Academy of Management Review & 1119 \\
Academy of Management Journal & 566 \\
Journal of Personality And Social Psychology & 527 \\
Journal of Applicative Psychology & 493 \\
Journal of Marketing Research & 487 \\
American Journal of Sociology & 468 \\
Strategic Management Journal & 428 \\
Administrate Science Quarterly & 428 \\
Social Science \& Medicine & 394 \\
\hline \hline
\end{tabular}

TABLE II: HIGHLY CITED DOCUMENTS: 2003-2007

\begin{tabular}{cl}
\hline \hline $\begin{array}{c}\text { Total } \\
\text { Citations }\end{array}$ & \multicolumn{1}{c}{ Full Citation Index For Document } \\
\hline 33 & Putnam R., 1993, Making Democracy Work \\
31 & Coleman JS, 1990, Foundations of social theory \\
29 & Mayer RC, 1995, Academy of Management Review, V20, P709. \\
27 & Morgan RM, 1994, Journal of Marketing, V58, P20. \\
24 & Fukuyama F., 1995, Trust Social Virtues \\
\hline \hline
\end{tabular}

TABLE III: HIGHLY CITED DOCUMENTS: 2008-2012

\begin{tabular}{cl}
$\begin{array}{c}\text { Total } \\
\text { Citations }\end{array}$ & \multicolumn{1}{c}{ Full Citation Index For Document } \\
\hline 85 & Mayer RC, 1995, Academy of Management Review, V20, P709. \\
85 & Morgan RM, 1994, Journal of Marketing, V58, P20. \\
81 & Putnam R.D., 2000, Bowling Alone Collapse \\
80 & Putnam R., 1993, Making Democracy Work \\
76 & Coleman JS, 1990, Foundations of social theory \\
69 & Rousseau DM, 1998, Academy of Management Review, V23, \\
61 & P393 \\
49 & Mcallister DJ, 1995, Academy of Management Journal, V38, P24. \\
48 & Doney PM, 1997, Journal of Marketing, V61, P35. \\
48 & Luhmann N., 1979, Trust Power
\end{tabular}

TABLE IV: HighLy CITED AUTHORS: 2003-2007

\begin{tabular}{cccc}
\hline \hline Author & Frequency & Author & Frequency \\
\hline Coleman JS & 40 & Dyer JH & 31 \\
Granovetter M & 39 & Gulati R & 31 \\
Putnam R. & 37 & Luhmann N. & 31 \\
Mayer RC & 35 & Williamson O. E. & 31 \\
Department of Health & 31 & Mechanic D & 30 \\
\hline \hline
\end{tabular}

Journal articles and books combined, the top five most cited scholar between 2003 and 2007 (the first five years) were Coleman J.S., Granovetter M., Putnam R., Mayer R.C., and Department of Health (Table IV). For the second five years, the status of the most important scholars changed. The top five most cited scholars were Coleman J.S., Gulati R., Mayer R. C., Rousseau D.M.P., Anderaon J.C. (Table V). These scholars have the most influence in the development of 
relations and trust area and thus collectively define this field. Their contributions represent the focus of the main research in the field and thus give us an indication of the popularity of certain relations and trust topics as well as their historical values.

Although the citation analysis does not eliminate the bias against younger scholars, a paper-based ranking (Table II and Table III) places more emphasis on the quality (as opposed to the quantity) of the documents produced by a given scholar than a ranking of authors based on the frequencies with which a particular author has been cited (as in Table IV and Table V). In addition, Table II and Table III represent the key research themes in a field and give us an indication of the popularity of certain relations and trust topics. The readers can find high citations are associated to what can be termed field-defining titles and they lay down the ground work for the understanding of relations and trust as a distinct phenomenon.

A comparison between Table II and Table III reveals some interesting patterns from the first five years (2003-2007) to the second five years (2008-2012). First, the top two most influential publications in the last decade changed, some researcher up but someone down, it means the main top is changed. The gradual increase in the total citations supports the evolving process of relations and trust research as an academic field and the process of gaining more and more recognition in the literature.

TABLE V: Highly CiTED AUTHORS: 2008-2012

\begin{tabular}{cccc}
\hline \hline Author & Frequency & Author & Frequency \\
\hline Coleman JS & 109 & Dyer JH & 94 \\
Gulati R & 102 & Granovetter M & 91 \\
Mayer RC & 102 & Morgan RM & 88 \\
Rousseau DM & 98 & Luhmann N. & 87 \\
Anderaon JC & 95 & Williamson O.E. & 87 \\
\hline \hline
\end{tabular}

\section{B. Co-citation Analysis}

In this stage, data mapping was conducted and an intellectual structure of current relations and trust studies was revealed. Co-citation analysis is a bibliometric technique that information scientists use to map the intellectual structure of an academic field. It involves counting documents from chosen field-paired or co-cited documents. Co-citation analysis compiles co-citation counts in matrix form and statistically scales them to capture a snapshot at a distinct point in time of what is actually a changing and evolving structure of knowledge [12].

Co-citations were tabulated for each source documents by using the Excel package. Many of the authors had very few co-citations that were either unlikely to have had a significant impact on the development of the field or were too new to have had time to impact on the literature. To facilitate analyses and improve the probability of its success, it was made sure that all authors in the final set had at least 25 citations in the first five years and 26 in the second five years. Based on the total number of citations in the selected journals, the top scholars were identified, and then a co-citation matrix was built before a pictorial map was drawn to describe the correlations among different scholars. In doing so, we were following the procedures recommended by White and Griffith [13].
Social network analysis techniques were used to graph the relationships in the co-citation matrix and identify the strongest links and the core areas of interest in relations and trust. Fig. 1 and Fig. 2 show the core research themes in relations and trust studies, based on sample articles with links of greater than or equal to ten co-citations shown in the network.

Different shapes of the nodes result from performing a faction study of these authors. This method seeks to group elements in a network based on the sharing of common links to each other. The diagrams show that current research in relations and trust area is concentrating on the interactions of essential of value relevance, positive relations theory, and Country-specific factors. The few scholars in Fig. 1 and Fig. 2 with the most links (co-citation) are the super stars in relations and trust research. Their heavy citations and intensive interlinks with each other undoubtedly indicate their prestigious status in relations and trust research and their publications and research work collectively define the future research directions of relations and trust studies.

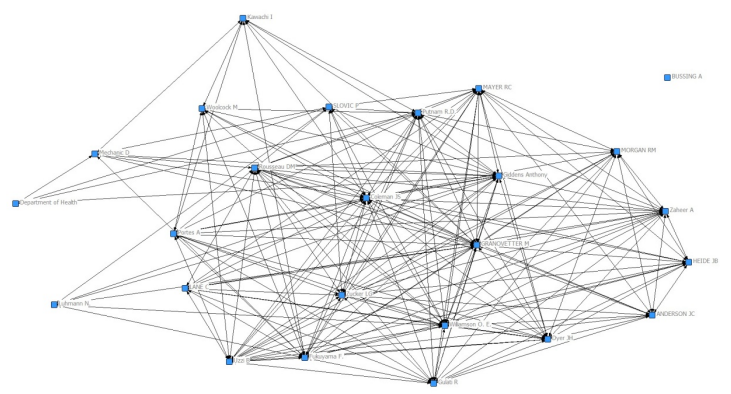

Fig. 1. Key research themes in relations and trust (2003-2007) (frequency 10)

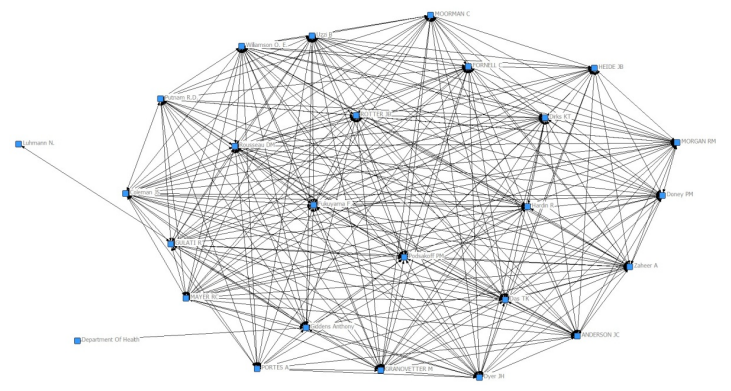

Fig. 2. Key research themes in relations and trust (2003-2012) (frequency 20)

While the diagrams in Fig. 1 and Fig. 2 provide a clear picture, their foci are only on the very core areas and only a limited amount of information is revealed. By taking the co-citation matrix and grouping the authors using factor analysis of the correlations between the entries, we can determine which authors are grouped together and therefore share a common element. According to this, the closeness of author points on such maps is algorithmically related to their similarity as perceived by citers. We use r-Pearson as a measure of similarity between author pairs, because it registers the likeness in shape of their co-citation count profiles over all other authors in the set [13].

The co-citation correlations matrix was factor analyzed using matrix rotation, a commonly used procedure, which attempts to fit (or load) the maximum number of authors on the minimum number of factors. The diagonals were considered missing data and were applied the criterion of 
omitting the two cases.

Six factors were extracted from the data in the first five years (2003-2007) and together they explained over $80.5 \%$ of the variance in the correlations matrix. Table VI lists the six most important factors along with the authors that had a factor loading of at least 0.5 . As is usual in this type of analysis, authors with less than a 0.5 loading or with cross-loadings were dropped from the final results [14]. We tentatively assigned names to the factors on the basis of our own interpretation of the authors with high loadings. Our interpretation of the analysis results is that relations and trust research in this period is composed of at least six different sub-fields: Trust of strategy organizing, social capital, Social system, work satisfaction, health policy and economic organizing (Fig. 1). We made no attempts to interpret the remaining factors due to their small Eigen values. They have also been excluded from Table VI.

Similarly, studies on relations and trust also clustered on different research themes between 2003 and 2012 and together they explained over $74.2 \%$ of the variance in the correlations matrix of the second four years, as pictured in Fig. 2. Table VII lists the five most important factors along with the authors that had a factor loading of at least 0.5 . We also tentatively assigned names to the factors on the basis of our own interpretation of the authors with high associated loadings. Our interpretation of the analysis results is that relations and trust research at this stage is also composed of at least five key subfields: interpersonal and organizing principle, social capital structure, leadership and performance, social system and Market trust factors.

Fig. 1 and Table VI clearly indicated that the most influential authors in relations and trust studies between 2003 and 2013 clustered together. The first factor in Table VI appears to define Trust of strategy organizing by Dyer J.H., Zucker L.G .and Zaheer. Factor 2 is defined by Woolcock M., Fukuyama F. and Portes A., and appears to Social capital relevance on relations and trust research.

TABLE VI: AUTHOR FACTOR LOADINGS: 2003-2007

\begin{tabular}{|c|c|c|c|}
\hline $\begin{array}{l}\text { Factor 1: Trust of } \\
\text { strategy organizing }\end{array}$ & Variance & $\begin{array}{c}\text { Factor 2: Social } \\
\text { capital }\end{array}$ & Variance \\
\hline Dyer J.H. & 0.87 & Woolcock M. & 0.925 \\
\hline Zucker L.G. & 0.87 & Fukuyama F. & 0.911 \\
\hline Zaheer A. & 0.864 & Portes A. & 0.855 \\
\hline Lane C. & 0.804 & Kawachi I. & 0.802 \\
\hline Heide J.B. & 0.793 & Giddens Anthony & 0.795 \\
\hline Gulati R. & 0.792 & Coleman J.S. & 0.776 \\
\hline Rousseau D.M. & 0.784 & Putnam R.D. & 0.669 \\
\hline Uzzi B. & 0.713 & Granovetter M. & 0.57 \\
\hline Morgan R.M. & 0.647 & & \\
\hline Williamson O.E. & 0.637 & & \\
\hline Anderson J.C. & 0.59 & & \\
\hline Mayer R.C. & 0.55 & & \\
\hline $\begin{array}{c}\text { Factor 3: } \\
\text { Social system }\end{array}$ & Variance & $\begin{array}{c}\text { Factor 4: } \\
\text { work satisfaction }\end{array}$ & Variance \\
\hline Slovic P. & 0.925 & Bussing A. & 0.945 \\
\hline Department of Health & 0.898 & Mayer R.C. & 0.72 \\
\hline Luhmann N. & 0.894 & & \\
\hline $\begin{array}{c}\text { Factor 5: } \\
\text { health policy }\end{array}$ & Variance & $\begin{array}{c}\text { Factor } 6 \text { : } \\
\text { economic organizing }\end{array}$ & Variance \\
\hline Mechanic D. & 0.748 & Williamson O.E. & 0.582 \\
\hline Putnam R.D. & 0.593 & Granovetter M. & 0.518 \\
\hline
\end{tabular}

Factor 3 represents Social system is defined by Slovic P.,
Department of Health and Luhmann N. Slovoc P. (1988) indicated a structural description of the social amplification of risk is possible. [15] Factor 4 represents work satisfaction is defined by Bussing A., Mayer R.C. and Anderson J.C. Mayer R.C \& Davis J.H.(1999). Factor 5 represents health policy is defined by Mechanic D. and Putnam R.D. Factor 6 represents economic organizing issues. There three types of trust in economic organization.

For the second five years, Fig. 2 and Table VII clearly indicated that the most influential authors in accounting standards studies between 2007 and 2012 also clustered together.

TABLE VII: AUTHOR FACTOR LOADINGS: 2008-2012

\begin{tabular}{cccc}
\hline \hline $\begin{array}{c}\text { Factor 1: } \\
\text { interpersonal \& } \\
\text { organizing principle }\end{array}$ & Variance & $\begin{array}{c}\text { Factor 2: } \\
\text { social capital } \\
\text { structure }\end{array}$ & Variance \\
\hline Das T.K. & 0.879 & Portes A. & 0.925 \\
Zaheer A. & 0.875 & Giddens Anthony & 0.909 \\
Dyer J.H. & 0.795 & Fukuyama F. & 0.908 \\
Williamson O. E. & 0.789 & Hardin R. & 0.862 \\
Uzzi B. & 0.767 & Putnam R.D. & 0.704 \\
Gulati R. & 0.699 & Coleman J.S. & 0.695 \\
Heide J.B. & 0.62 & Granovetter M. & 0.561 \\
\hline \hline Factor 3: & & Factor 4: & Variance \\
eldership \& & Variance & social system & 0.938 \\
performance & & Luhmann N. & 0.925 \\
\hline Dirks K.T. & 0.902 & Department of Health & \\
Rotter J.B. & 0.863 & & \\
Rousseau D.M. & 0.79 & & \\
Mayer R.C. & 0.528 & & \\
\hline \hline Factor 5: & Variance & & \\
Market trust factors & 0.884 & & \\
\hline Podsakoff P.M. & 0.853 & & \\
Moorman C. & 0.819 & & \\
Doney P.M. & 0.769 & & \\
Morgan R.M. & 0.72 & & \\
Anderson J.C. & 0.613 & & \\
Heide J.B. & & & \\
\hline \hline
\end{tabular}

The first factor in Table VII appears to define the intrinsic value of relations and trust is defined by Das T.K., Zaheer A. and Dyer J.H. Das T.K. Factor 2 is social capital, it defined by Portes A. (1998) distinguished four sources of social capital and examines their dynamics [16]. Factor 3 represents leadership and performance is defined by Dirks K.T., Rotter J.B. and Rousseau D.M. numerous researchers seem to agree that trust has a number of important benefits for organizations [17]. Factor 4 represents social system that is defined by Luhmann N., Department of Health. Factor 5 represents market trust is defined by Podsakoff P.M., Moorman C., and Doney P.M.

\section{Tag Cloud Analysis}

Tag clouds have proliferated over the relations and trust in the past decade. One of the most exciting recent developments in relations and trust is social network that enables users to easily annotate relations and trust form keywords [18] [19]. They provide a visualization of a collection of simple texts by visually depicting the tag frequency by font size.

Compared with the first five years tag cloud and the 
second five years tag cloud (Fig. 3 and Fig. 4), we can find the different in the key words' fond size. In the second five years researcher concerned trust more than relations, and social's size is almost equal to relations .Its seems meaning something to advance understanding.

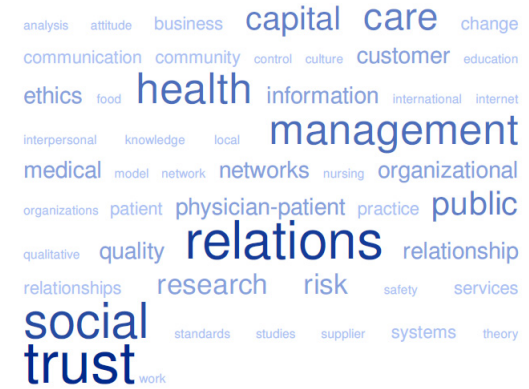

Fig. 3. Tag clouds in key word of relations and trust (2003-2007)

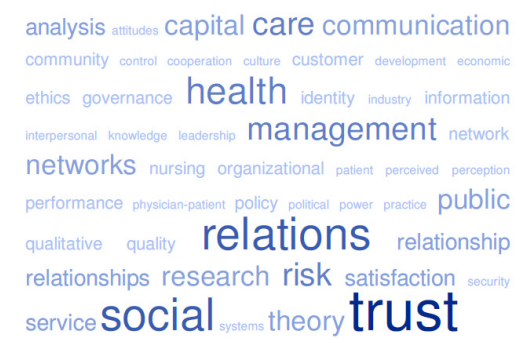

Fig. 4. Tag clouds in key word of relations and trust (2008-2012)

\section{CONCLUSION}

The past ten years have seen extensive research on relations and trust. This study investigates relations and trust research using citation and co-citation data published in SSCI between 2003 and 2012. With a factor analysis of the co-citation data, this study maps the intellectual structure of relations and trust research, which suggests that the contemporary relations and trust research is organized along different concentrations of interests: interpersonal \& organizing principle, social capital structure, leadership \& performance, social system and Market trust factors.

The mapping of the intellectual structure of relations and trust studies indicates that relations and trust has somehow created its own literature and that it has gained the reputation as a legitimate academic field, with relations and trust specific journals gaining the status required for an independent research field, such as the Journal of Marketing. Given that the relations and trust is still young and our analysis has shown that it has an evolving structure, it is believed that relations and trust publication outlets will gain more popularity and prestige that is required to become a more prominent academic field when we learn more about current paradigms and the key research themes in relations and trust studies, how they relate, and what they stand for. With more scholars and more resources contributing to the relations and trust area, a better academic environment conducive for research ideas' cross-fertilizing will be formed and a relations and trust, as a field, will gain more momentum for further development.

\section{REFERENCES}

[1] J. S. Coleman, "Commentary: Social Institutions and social theory," Foundations of Social Theory, 1990.

[2] R. C. Mayer, "An integrative model of organizational trust," Academy of Management Review, vol. 20, pp. 709, Jul. 1995.

[3] O. E. Williamaon, " Calculativeness, Trust, and Economic Organization," Journal of Law and Economics, vol. 36, no. 1, pp. 453-486, Apr. 1993

[4] A. Pilkington and T. Teichert, "Management of technology: Themes, concepts and relationships," Techinnovation, vol. 26, pp. 288-299, Mar. 2006.

[5] E. Garfield, Citation Indexing: Its Theory and Application in Science, Technology, and Humanities, New York: Wiley, 1979.

[6] L. J. Ponzi, "The intellectual structure and interdisciplinary breadth of knowledge management: A bibliometric study of its early stage of development," Scientometrics, vol. 55, pp. 259-272, Aug. 2002.

[7] H. Etemad, "E-commerce: The emergence of a field and its knowledge network," International Journal of Technology Management, vol. 28, pp. 776-800, Dec. 2004.

[8] A. R. R. Rodriguez and J. R. Navarro, "Changes in the intellectual structure of strategic management research: Abibliometric study of the strategic management journal, 1980-2000," Strategic Management Journal, vol. 25, pp. 981-1004, Aug. 2004.

[9] F. J. Acedo, and J. C. Casillas, "Current paradigms in the international management field: An author co-citation analysis," International Business Review, vol. 14, pp. 619-639, Oct. 2005.

[10] K. C. Chan, G. S. Seow, and K. T. Am, "Ranking accounting journals using dissertation citation analysis: A research note," Accounting Organizations and Society, vol. 34, pp. 875-885, Aug-Oct. 2009.

[11] J. Park et al., "A vector space approach to tag cloud similarity ranking," Information Processing Letters, vol. 110, no. 12-13, pp. 489-496, Jun. 2010.

[12] R. M. Morgan, "The Commitment-Trust Theory of Relationship Marketing," Journal of Marketing, vol. 58 , Jul. 1994

[13] D. H. White and K. W. Cain, "Visualizing a discipline: An author co-citation analysis of information science," Journal of the American Society for Information Science, vol. 49, pp. 327-355, Dec. 1998.

[14] H. White and B. Griffith, "Author co-citation: A literature measure of intellectual structure," Journal of the American Society for Information Science, vol. 32, no. 3, pp. 163-171, May. 1981.

[15] P. Slovic, "The Social Amplification of Risk: A Conceptual Framework," vol. 8, no. 2, pp. 177-187, Jun. 1988

[16] A. Portes, Social Capital: Its Origins and Applications in Modern Sociology, Butterworth-Heinemann, 2000.

[17] K. T. Dirks and D. L. Ferrin, "The Role of Trust in Organizational Settings," Organization Science, vol. 12, no. 4, pp. 450-467, Jul/Aug 2001.

[18] B. Lee et al., "Spark Clouds: Visualizing Trends in Tag Clouds," IEEE Transaction in Visualization and Computer Graphics, vol. 16 no. 6, pp. 1182-1189, Oct. 2010.

[19] P. Slovic, "Perception of Risk," Science, vol. 236, no. 4799, pp. 280-285, Apr. 1987

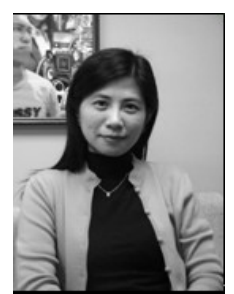

Ying-Shao Chang is the lecturer of Department of Mass Communication, Chang Jung Christian University and the executive of Star Radio Station, Chang Jung Christian University Now she is also a doctoral student at graduate School of Business management, Chang Jung Christian University in Taiwan. Her research interests include media management, public relations and audience behavior.

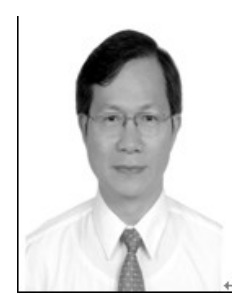

Jen-Hwa Kuo is a doctoral student at Graduate School of Business management, Chang Jung Christian University in Taiwan. He received MS degree from the Graduate Institute of Industrial Economics in National Central University, Taiwan. His research interests include enterprise resource planning, management information system and accounting. 